\title{
Erratum to: Validation of the Animated Activity Questionnaire (AAQ) for patients with hip and knee osteoarthritis: comparison to home-recorded videos
}

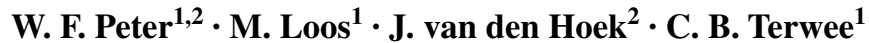

Published online: 16 October 2015

C) Springer-Verlag Berlin Heidelberg 2015

\section{Erratum to: Rheumatol Int (2015) 35:1399-1408 \\ DOI 10.1007/s00296-015-3230-4}

Unfortunately, the funding information was omitted in the Acknowledgments section of the published article. The revised Acknowledgments section is given below.

Acknowledgments This work was Financially supported by Anna FoundationlNOREF, and the European League Against Rheumatism (EULAR).

The online version of the original article can be found under doi:10.1007/s00296-015-3230-4.

W. F. Peter

w.peter@vumc.nl

M. Loos

mickloos@hotmail.com

J. van den Hoek

j.vd.hoek@reade.nl

C. B. Terwee

cb.terwee@vumc.nl

1 Department of Epidemiology and Biostatistics and the EMGO Institute for Health and Care Research, VU University Medical Centre, De Boelenlaan 1089a, 1081 HV Amsterdam, The Netherlands

2 Amsterdam Rehabilitation Research Centre I Reade, Amsterdam, The Netherlands 